Bull. Chem. Soc. Ethiop. 2014, 28(3), 329-338.

Printed in Ethiopia

DOI: http://dx.doi.org/10.4314/bcse.v28i3.2

ISSN 1011-3924

(c) 2014 Chemical Society of Ethiopia

\title{
TRACE DETERMINATION OF BISPHENOL-A IN LANDFILL LEACHATE SAMPLES BY DISPERSIVE LIQUID-LIQUID MICROEXTRACTION FOLLOWED BY HIGH PERFORMANCE LIQUID CHROMATOGRAPHY
}

\author{
Nader Bahramifar ${ }^{1}$, Reyhaneh Rahnama ${ }^{2 *}$ and Sam Saberimoghaddam ${ }^{2}$ \\ ${ }^{1}$ Department of Environmental Science, Faculty of Natural Resources, Tarbiat Modares \\ University, P.O. Box 46414-356, Noor, Iran \\ ${ }^{2}$ Department of Chemistry, Payame Noor University, P.O. Box 19395-3697 Tehran, Iran
}

(Received November 6, 2013; revised June 9, 2014)

\begin{abstract}
A simple, rapid and efficient sample pretreatment technique, termed dispersive liquid-liquid microextraction (DLLME), was developed as an extraction methodology to determine bisphenol-A (BPA), in landfill leachate samples prior to high performance liquid chromatography (HPLC)-ultraviolet detection. Some effective parameters, such as $\mathrm{pH}$, extraction and disperser solvent type and their volumes, time of extraction and salt effect have been optimized using the one-factor-at-a-time approach. Under the optimum conditions, the preconcentration factor 25 was obtained from only $5 \mathrm{~mL}$ of the sample. The calibration graph was linear in the range of 5-500 $\mu \mathrm{g} \mathrm{L}{ }^{-1}$ with the detection limit of $1.5 \mu \mathrm{g} \mathrm{L}{ }^{-1}$. The relative standard deviation (RSD) for ten replicate measurements of $20 \mu \mathrm{g} \mathrm{L}^{-1}$ of BPA was $2.5 \%$. Finally, the method was successfully applied for the extraction and determination of BPA in some landfill leachate samples with a relative recovery of $98-109 \%$ and RSD less than $5 \%$.
\end{abstract}

KEY WORDS: Dispersive liquid-liquid microextraction, Bisphenol-A, Landfill leachate samples, Highperformance liquid chromatography

\section{INTRODUCTION}

In recent years, a specific category of human made chemicals, commonly called endocrine disrupting chemicals (EDCs), has attracted a great deal of public and scientific attention because of their suspected carcinogenic and estrogenic properties. They have been known to interfere with endocrine systems by mimicking, blocking and triggering actions of hormones and thereby influencing the health and reproductive system of humans and animals [1]. EDCs are members of different groups of chemicals, including drugs, pesticides, industrial by-products, alkyl phenols, synthetic steroids, and so on.

Among phenolic EDCs, 2,2-bis(4-hydroxyphenyl) propane, bisphenol A (BPA), has generated the most concern among regulatory agencies and scientists due to its high production, widespread use and ubiquitous occurrence in the environment [2]. BPA is one of the highvolume chemicals produced worldwide, with an estimated production of 3.9 million tons in 2006 [3] and over 100 tons released into the atmosphere from its annual production [4]. It is mainly used as a monomer in the synthesis of polycarbonates, thus being a ubiquitous ingredient in a variety of consumer goods including reusable water bottles, compact disks and medical devices. BPA also plays an important role in the production of epoxy resins which are applied as protective linings in food and beverage cans [5]. BPA exists widely in the environment and can easily enter the human body to produce adverse health effects. In addition to its negative effects on endocrine systems, low-dose BPA might also result in increased risks of diabetes mellitus, cardiovascular diseases and liver-enzyme abnormalities [6]. Currently, the tolerable daily intake set by the European Union (EU) Commission [7] and the reference dose established by the US Environmental Protection Agency (EPA) [8] is $0.05 \mathrm{mg} \mathrm{BPA} \mathrm{kg}{ }^{-1}$ body weight/day [9]. The increased global concern about this compound highlights the importance of developing selective and sensitive analytical methods to detect trace BPA in environmental, biological and foodstuff samples.

*Corresponding author. E-mail: r_rahnama@ymail.com 
To date, various analytical methods have been developed and used for the determination of BPA. Such methods include liquid chromatography (LC), liquid chromatography-mass spectrometry (LC-MS), gas chromatography-mass spectrometry (GC-MS), liquid chromatography with electrochemical detector (LC-ECD), chemiluminescence, enzyme-linked immunosorbent assay (ELISA), and electrochemical techniques [10-15]. Sample clean-up forms a major part in the determination of traces of BPA in complex matrices. It is commonly necessary to remove interfering matrix compounds to increase selectivity and to enrich BPA in order to lower the limit of detection (LOD). Various sample pretreatment techniques such as liquid-liquid extraction (LLE) [16], solid phase extraction [17], cloud point extraction [18], solid phase microextraction [19] and liquid phase microextraction [20], are used for the preconcentration of BPA in various samples.

Recently, a microextraction technique as a high performance and powerful preconcentration method termed dispersive liquid-liquid microextraction (DLLME) was demonstrated by Assadi and colleagues [21]. DLLME has gained increased prominence for its rapidity, simplicity, cheapness, environmental friendliness and ability to provide high extraction efficiencies. It is based on a ternary component solvent scheme. Briefly, a cloudy mixture (microdroplets) is formed when a mixture of an extraction solvent (typical non-miscible organic solvent used in classical LLE or ionic liquids) and disperser solvent (miscible organic solvents, e.g. methanol, acetone, acetonitrile, etc.) is rapidly injected into an aqueous sample. Due to the large contact surface area of the two immiscible phases, high extraction efficiency is achieved in a relatively short time. After extraction and phase separation, the organic solvent is collected and analyzed. DLLME has been successfully applied for the preconcentration of several trace analytes in water and environmental samples [22-26]. However, its application to complex matrices such as milk and dairy products is still very limited.

The aim of this study is to develop a simple and rapid method for the extraction, enrichment, and determination of BPA in landfill leachate samples that is one of the most probable sources of BPA found in environmental samples [27]. Leaching of pollutants from point sources such as landfills can result in the contamination of aquatic environments, including drinking water reservoirs. One important factor makes the analysis of organic pollutants in landfill leachate samples difficult compared with, for example, drinking water analysis. The matrix is very complex, consisting of high concentrations of humic and fulvic acids as well as salts, which can interfere with the detection or reduce analyte recovery [28]. Therefore, preconcentration, sample clean up and selective detection are required.

The objective of the present work is to investigate the possibility of using DLLME combined with high performance liquid chromatography-ultraviolet detection (HPLC-UV) for the analysis of BPA in landfill leachate samples.

\section{EXPERIMENTAL}

\section{Apparatus}

A HPLC system from Knauer (Germany) was used for the analysis. This system equipped with start line pump 1000, UV detector model Basic 2500 set as $215 \mathrm{~nm}$ and model D-14163 Berlin manual injector with a $20 \mu \mathrm{L}$ sample loop. The analyte was separated by an isocratic elution on a Eurospher 100-5-C18 column $(25 \mathrm{~cm} \times 4.5 \mathrm{~mm}$, particle size: $5 \mu \mathrm{m})$ from Berlin (Germany) using water:acetonitrile (40:60, v/v) as mobile phase. The mobile phase was delivered with a flow rate of $1 \mathrm{~mL} \mathrm{~min}^{-1}$ at room temperature. A Hettich centrifuge (Model EBA 20, Germany) was used for accelerating the phase separation. The $\mathrm{pH}$ values were measured with a Metrohm pH-meter (model: 827) supplied with a glass-combined electrode. An ultrasonic bath model LC E $60 \mathrm{H}$ Germany was used for mixing solutions. 


\section{Reagents and materials}

2,2-Bis(4-hydroxyphenyl) propane, bisphenol A (BPA) was purchased from Merck (Darmstadt, Germany). All of the solvents including acetone, acetonitrile (HPLC grade), ethanol, methanol, chloroform, dichloromethane, carbon tetrachloride and chlorobenzene were obtained from Merck (Darmstadt, Germany). Also, sodium nitrate $\left(\mathrm{NaNO}_{3}, 99 \%\right)$, sodium hydroxide $(\mathrm{NaOH}$, 99\%), hydrochloric acid ( $\mathrm{HCl}, 37 \%)$ and HPLC grade water were from Merck (Darmstadt, Germany). Nitric acid $\left(\mathrm{HNO}_{3}, 65 \%\right)$ was purchased from Sharlau (Spain). All the reagents were analytical reagent grade. A stock solution containing BPA at $1000 \mathrm{mg} \mathrm{L}^{-1}$ was prepared in methanol. The working standard solutions were prepared by appropriate stepwise dilution of the stock standard solution with deionized water. All the standard solutions were stored at $4{ }^{\circ} \mathrm{C}$.

\section{Sample collection and preparation}

Samples were collected from two landfills in Babolsar and Noor (Mazandaran Province, Iran). These samples were prepared by filtering and centrifuging them in order to eliminate solid matrices from them. Then, $\mathrm{pH}$ of the samples was adjusted to 13 and centrifuged again. It should be emphasised that as the $\mathrm{pH}$ of landfill leachate increased up to 13 , the dissolved organic and inorganic matters can be removed by means of chemical precipitation and coagulation from the solution. However, BPA tends to be negatively charged at $\mathrm{pH}$ greater than 13 and remained in sample solution. At the end, color of the sample solution changes from dark brown to light yellow. After filtration, $\mathrm{pH}$ adjustment $(\mathrm{pH}=4)$ was done by adding $\mathrm{HCl}$ and their content for BPA was investigated.

\section{Extraction procedure}

A $5 \mathrm{~mL}$ sample containing BPA was placed in a $10 \mathrm{~mL}$ test tube with a conical bottom. Then $0.1 \mathrm{~mL}$ of $0.1 \mathrm{~mol} \mathrm{~L}^{-1}$ sodium acetate/acetic acid buffer $(\mathrm{pH}=4)$ was added. A mixture consisting of $0.75 \mathrm{~mL}$ acetone (dispersive solvent) and $100 \mu \mathrm{L}$ chloroform (extraction solvent) was injected rapidly into the sample using a 1-mL syringe (Gastight, Hamilton, Nevada, USA). A cloudy solution (resulting from the dispersion of the fine droplets of chloroform in the aqueous sample) was formed in the test tube. The mixture was then centrifuged at $5000 \mathrm{rpm}$ for 6 min. After centrifuging, the sedimented phase was completely transferred into another test tube and after evaporation of the solvent the residue was dissolved in $200 \mu \mathrm{L}$ of HPLC-grade methanol and then, $20 \mu \mathrm{L}$ of the final solution was injected into the HPLC.

\section{RESULTS AND DISCUSSION}

In order to optimize the DLLME procedure, $5.0 \mathrm{~mL}$ double-distilled water spiked with $20 \mu \mathrm{g} \mathrm{L}^{-1}$ of BPA was used to study the extraction performance of the DLLME under different experimental conditions. Various parameters including the type and the volume of the extraction solvent, the type and the volume of the dispersive solvent, the extraction time and the ionic strength were optimized. These experiments were performed at $\mathrm{pH} 4.0$ by adding the sodium acetate/acetic acid buffer solution. Because BPA is weakly acidic compound ( $\mathrm{pK}_{\mathrm{a}}$ 9.73) [29], a high $\mathrm{pH}$ can cause the ionization of BPA under investigation. The ionic form of analyte does not interact with chloroform as strongly as does its neutral form. As a result, smaller amount of analyte is extracted [30]. Moreover BPA is soluble in alkaline environment, so it is hard to be extracted [31]. Thus, $\mathrm{pH} 4.0$ was selected as working condition. One-variable-at-a-time optimization was used to obtain the optimum condition. All the experiments were performed in triplicate, and the average of the results was reported in figures or tables. Extraction efficiency (\%) obtained from calibration cure of direct injection of BPA standard solutions. Finally, these optimal conditions were applied to extract and detect BPA in the real samples. 
Selection of extraction solvent

Proper selection of extraction solvent plays a crucial role in any dispersive liquid-liquid microextraction procedure. This solvent has to meet some requirements: the extraction solvent has to be insoluble in water and able to extract the analytes of interest. Also, it should have low volatility and low toxicity, must not interfere with the analytical techniques used for the determination of analytes [21] and must have a density different than the density of the water sample to enable phase separation after extraction. Chlorobenzene (density, $1.11 \mathrm{~g} \mathrm{~mL}^{-1}$ ), carbon tetrachloride (density, $1.59 \mathrm{~g} \mathrm{~mL}^{-1}$ ), dichloromethane (density, $1.32 \mathrm{~g} \mathrm{~mL}^{-1}$ ) and chloroform (density, $1.48 \mathrm{~g} \mathrm{~mL}^{-1}$ ) were studied as extraction solvents using a mixture of $0.75 \mathrm{~mL}$ acetone and different volumes of chloroform, chlorobenzene, carbon tetrachloride and dichloromethane, to achieve a volume equal to that of the sedimented phase. After DLLME, the sedimented phase was completely evaporated, the residue was dissolved in $200 \mu \mathrm{L}$ of methanol and then, $20 \mu \mathrm{L}$ of the final solution was injected into the HPLC. Figure 1 shows the effect of the type of extraction solvent on the extraction efficiency of BPA. The results revealed that chloroform has the highest extraction efficiency in comparison with chlorobenzene, carbon tetrachloride and dichloromethane for a $20 \mu \mathrm{g} \mathrm{L}^{-1}$ solution of BPA. Therefore, chloroform was selected as the extraction solvent for further experiments.

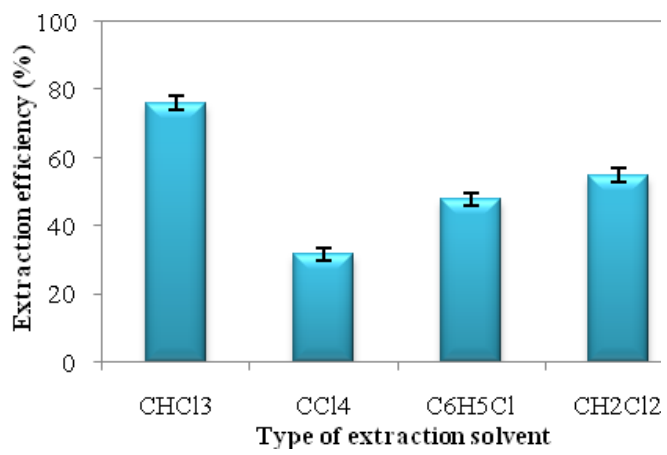

Figure 1. Effect of type of the extraction solvent on the extraction efficiency of BPA. Extraction conditions: water sample volume, $5.0 \mathrm{~mL} ; \mathrm{pH}=4$; dispersive solvent (acetone) volume, $0.75 \mathrm{~mL}$; concentration of BPA, $20 \mu \mathrm{g} \mathrm{L}{ }^{-1}$.

The effect of the volume of extraction solvent

The influence of the extraction solvent volume on the extraction efficiency of BPA was examined within the range of $60-200 \mu \mathrm{L}$ and using $0.75 \mathrm{~mL}$ acetone as dispersive solvent according to the same DLLME procedure. The results are shown in Figure 2. These results reveal that $100 \mu \mathrm{L}$ was the lowest amount of chloroform required to achieve satisfactory recoveries. It is clear that in solutions with low volumes of chloroform (lower than $100 \mu \mathrm{L}$ ) the amount of chloroform is not enough for the extraction of BPA, hence, extraction efficiency is low. Also, higher amounts of chloroform did not improve extraction efficiency. Therefore, the amount of $100 \mu \mathrm{L}$ chloroform was used for subsequent experiments.

Selection of dispersive solvent

The dispersive solvent has a key role in DLLME. This importance emerges from the ability of the dispersive solvent to make the extraction solvent form very fine droplets in the water solution. Moreover, the dispersive solvent should be miscible in the extraction solvent and water 
solution. Thus, several dispersive solvents were investigated including acetone, methanol, ethanol and acetonitrile (Figure 3). The results showed that acetone gave higher extraction efficiency compared to methanol, ethanol and acetonitrile. Therefore, it was selected as the dispersive solvent.

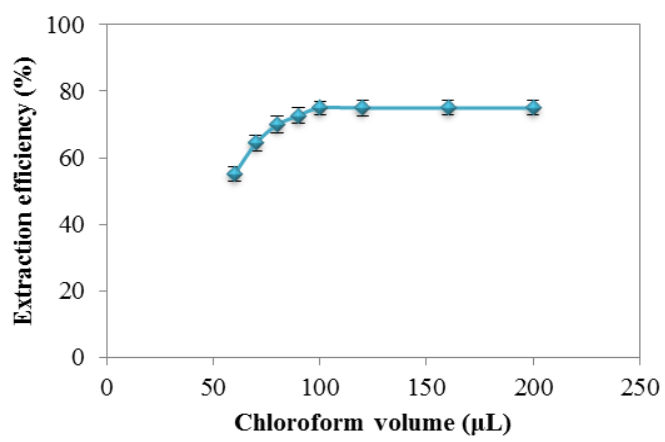

Figure 2. Effect of the volume of extraction solvent on the extraction efficiency of BPA. Extraction conditions: water sample volume, $5.0 \mathrm{~mL} ; \mathrm{pH}=4$; extraction solvent, chloroform; dispersive solvent (acetone), $0.75 \mathrm{~mL}$; concentration of BPA, $20 \mu \mathrm{g} \mathrm{L}^{-1}$.



Figure 3. Effect of type of the dispersive solvent on the extraction efficiency of BPA. Extraction conditions: water sample volume, $5.0 \mathrm{~mL} ; \mathrm{pH}=4$; extraction solvent (chloroform) volume, $100 \mu \mathrm{L}$; dispersive solvent volume, $0.75 \mathrm{~mL}$; concentration of BPA, $20 \mu \mathrm{g}$ $\mathrm{L}^{-1}$.

\section{The effect of the volume of dispersive solvent}

After choosing acetone as dispersive solvent, it is necessary to optimize its volume. For obtaining an optimized volume of acetone, various experiments were performed by using different volumes of acetone $(0.25,0.50,0.75,1.00,1.25,1.50,2.00 \mathrm{~mL})$ containing 110,115 , $120,125,130,135$ and $140 \mu \mathrm{L}$ chloroform, respectively. It is necessary to change the volume of chloroform by changing the volume of acetone in order to obtain a constant volume of sedimented phase in all experiments. Figure 4 shows the curves of the extraction efficiency of BPA versus the volume of acetone. At lower volumes of dispersive solvent, the formation of tiny droplets may not be effective thereby lowering the extraction efficiency. However, at higher dispersive solvent volumes, the solubility of the analyte increases, lowering analyte partition 
with extractant droplets and leading to a decrease in its efficiency. According to the results, a $0.75 \mathrm{~mL}$ acetone was chosen as the optimum volume.

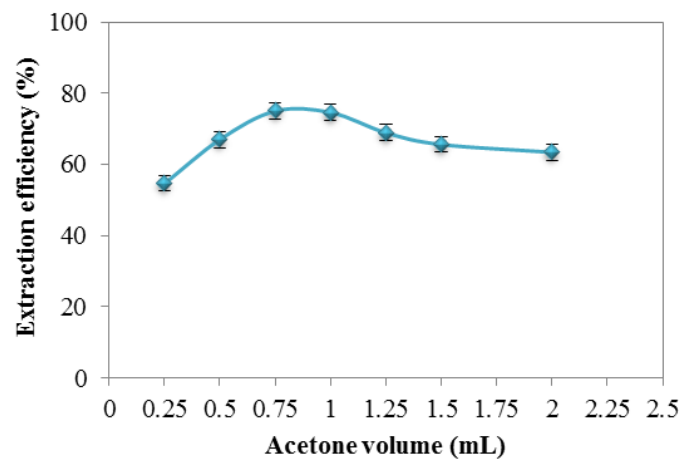

Figure 4. Effect of the volume of dispersive solvent on the extraction efficiency of BPA. Extraction conditions: water sample volume, $5.0 \mathrm{~mL} ; \mathrm{pH}=4$; extraction solvent, chloroform; dispersive solvent, acetone; concentration of BPA, $20 \mu \mathrm{g} \mathrm{L}^{-1}$.

\section{The effect of extraction time}

In DLLME, extraction time is defined as the time interval from the beginning of the dispersion and its end just before centrifugation. For evaluating this effect, different extraction times (ranging from 0 to $15 \mathrm{~min}$ ) with constant experimental conditions were studied. The results clearly revealed that the proposed extraction method is very fast so that the extraction time has no measurable effect on the extraction efficiency. This result is in agreement with previous reports $[32,33]$. This is indicative of the very large surface area between the extraction solvent and the aqueous sample. Therefore, the transition of the analyte from the aqueous phase to the extraction solvent is fast. Subsequently, the equilibrium state is achieved quickly after the injection of the extraction solvent into the sample solution. Time independence is indeed the most important advantage of DLLME.

\section{The effect of centrifuging rate and time}

For an acceptable separation result, the effect of centrifugation rate and time on the extraction efficiency was studied. The effect of centrifugation rate was investigated within the range of $1000-6000 \mathrm{rpm}$. It was found that over $4000 \mathrm{rpm}$, the organic phase completely settled. Therefore, the rate of $5000 \mathrm{rpm}$ was selected as the optimum point. At the optimum rate, extraction efficiency was examined as a function of centrifugation time. Over $6 \mathrm{~min}$, extraction efficiency was constant, indicating a complete transfer of the organic phase to the bottom of the centrifuge tube. So, the optimum centrifugation time was chosen as 6 min.

\section{The influence of ionic strength}

The influence of salt addition on the performance of DLLME was investigated by adding different amounts of $\mathrm{NaNO}_{3}\left(0-1 \mathrm{~mol} \mathrm{~L}^{-1}\right)$ into water samples while the other conditions were kept constant during extraction. Addition of salt to the water sample may have various effects on the extraction (salting-out, salting-in or no effect). In our study, no change in extraction efficiency of BPA was observed when the $\mathrm{NaNO}_{3}$ concentration was increased from 0 to $1 \mathrm{~mol}$ $\mathrm{L}^{-1}$. Thus, no salt was added in subsequent experiments. 


\section{Analytical performance of the method and its comparison with other methods}

Under the aforementioned optimum conditions, linear range, precision and detection limit were investigated. Good linear relationship was found in the concentration range of 5-500 $\mu \mathrm{g} \mathrm{L}^{-1}$ with a correlative coefficient $\left(\mathrm{R}^{2}\right)$ of 0.9997 . The precision of this method was determined by analyzing the standard solution at $20 \mu \mathrm{g} \mathrm{L}^{-1}$ of BPA for ten times continuously, following which the relative standard deviation (RSD) obtained was $2.5 \%$. The limit of detection (LOD) of the proposed method, based on a signal-to-noise ratio $(\mathrm{S} / \mathrm{N}=3)$ was $1.5 \mu \mathrm{g} \mathrm{L}^{-1}$. The preconcentration factor was 25 for $5.0 \mathrm{~mL}$ of the sample solution. These results show that this method could be well used to monitor the concentration of BPA in water samples.

The efficiency of the presented DLLME method for BPA was compared with other sample preparation techniques such as molecularly imprinted solid phase extraction [34], solid phase extraction [35], molecularly imprinted solid phase microextraction [36], in-tube solid phase microextraction [37], liquid phase microextraction gas chromatography mass spectrometry [38], hollow fiber assisted liquid-phase microextraction gas chromatography mass spectrometry [39] and solid phase extraction liquid chromatography mass spectrometry [40] from the viewpoint of linearity, LOD, RSD and preconcentration factor which are shown in Table 1. It can be observed that the analytical performance of the present method is comparable with other reported extraction methods except methods coupled with mass detector. These coupled techniques are time-consuming and expensive. In addition, these techniques also require skilled operators and complicated instrumentations. It is well known that HPLC-UV method has the advantages of fast response speed, cheap instrument, inexpensiveness, simple operation and timesaving. These characteristics are of great interest for the routine laboratories interested in the trace analysis of BPA.

Table 1. Comparison of DLLME with other extraction methods for determination of BPA.

\begin{tabular}{|l|c|c|c|c|c|c|}
\hline Method & $\begin{array}{c}\mathrm{LR}^{\mathrm{a}} \\
\left(\mu \mathrm{g} \mathrm{L}^{-1}\right)\end{array}$ & $\begin{array}{c}\mathrm{LOD}^{\mathrm{b}} \\
\left(\mu \mathrm{g} \mathrm{L}^{-1}\right)\end{array}$ & $\begin{array}{c}\mathrm{RSD}^{\mathrm{c}} \\
(\%)\end{array}$ & PF $^{\mathrm{d}}$ & $\begin{array}{c}\text { Sample } \\
\text { volume }(\mathrm{mL})\end{array}$ & Ref. \\
\hline MISPE-CE $-U V$ & - & 5.4 & 5.8 & 20 & 50 & 34 \\
\hline SPE-HPLC-FLD $^{\mathrm{f}}$ & $5-5000$ & 1.9 & 2.8 & - & - & 35 \\
\hline MISPME-HPLC-DAD & $15-400$ & 7.6 & 7.9 & - & 2.5 & 36 \\
\hline In-tube-SPME-HPLC-UV & $10-1000$ & 2.8 & 2.7 & - & 0.5 & 37 \\
\hline LPME-GC-MS & $2.5-250$ & 0.015 & 10.9 & 105 & 200 & 38 \\
\hline HF-LPME -GC-MS & $0.1-50$ & 0.02 & 6.7 & - & - & 39 \\
\hline SPE-LC-MS & $0.3-200$ & 0.1 & - & - & - & 40 \\
\hline DLLME-HPLC-UV & $5-500$ & 1.5 & 2.5 & 25 & 5 & This work \\
\hline
\end{tabular}

${ }^{\mathrm{a}}$ Linear range. ${ }^{\mathrm{b}}$ Limit of detection. ${ }^{\mathrm{c}}$ Relative standard deviation. ${ }^{\mathrm{d}}$ Preconcentration factor. ${ }^{\mathrm{e}}$ Molecularly imprinted solid phase extraction-capillary electrophoresis. ${ }^{\mathrm{f}}$ Fluorescence detector. ${ }^{\mathrm{g}}$ Diode array

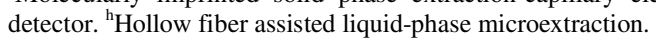

\section{Analysis of real samples}

The feasibility and reliability of the present method were verified through the analysis of BPA in two landfill leachate samples from Babolsar and Noor, Iran. The characteristics of the landfill leachate samples are shown in Table 2. All the analytical methods used for characterization of landfill leachate were according to "Standard methods for examination of water and wastewater" [41]. 
Table 2. Physicochemical characteristics of landfill leachate samples.

\begin{tabular}{|l|c|c|c|c|c|c|c|}
\hline Sample & $\mathrm{pH}$ & $\begin{array}{c}\mathrm{EC}^{\mathrm{a}} \\
\left(\mu \mathrm{sm}^{-1}\right)\end{array}$ & $\begin{array}{c}\mathrm{COD}^{\mathrm{b}} \\
\left(\mathrm{mg} \mathrm{L}^{-1}\right)\end{array}$ & $\begin{array}{c}\mathrm{BOD}^{\mathrm{c}} \\
\left(\mathrm{mg} \mathrm{L}^{-1}\right)\end{array}$ & $\begin{array}{c}\mathrm{TDS}^{\mathrm{d}} \\
\left(\mathrm{mg} \mathrm{L}^{-1}\right)\end{array}$ & $\begin{array}{c}\mathrm{TS}^{\mathrm{e}} \\
\left(\mathrm{mg} \mathrm{L}^{-1}\right)\end{array}$ & $\begin{array}{c}\mathrm{TKN}^{\mathrm{f}} \\
\left(\mathrm{mg} \mathrm{L}^{-1}\right)\end{array}$ \\
\hline Noor landfill leachate & 6.8 & 7.25 & 4733 & 3417 & 4537 & 5383 & 1709 \\
\hline Babolsar landfill leachate & 7.1 & 6.38 & 7347 & 4100 & 4109 & 7383 & 1649 \\
\hline
\end{tabular}

${ }^{\mathrm{a}}$ Electrical conductivity. ${ }^{\mathrm{b}}$ Chemical oxygen demand. ${ }^{\mathrm{c} B i o c h e m i c a l}$ oxygen demand. ${ }^{\mathrm{d}}$ Total dissolved solids. ${ }^{\mathrm{e}}$ Total solids. ${ }^{\mathrm{f}}$ Total Kjeldahl nitrogen.

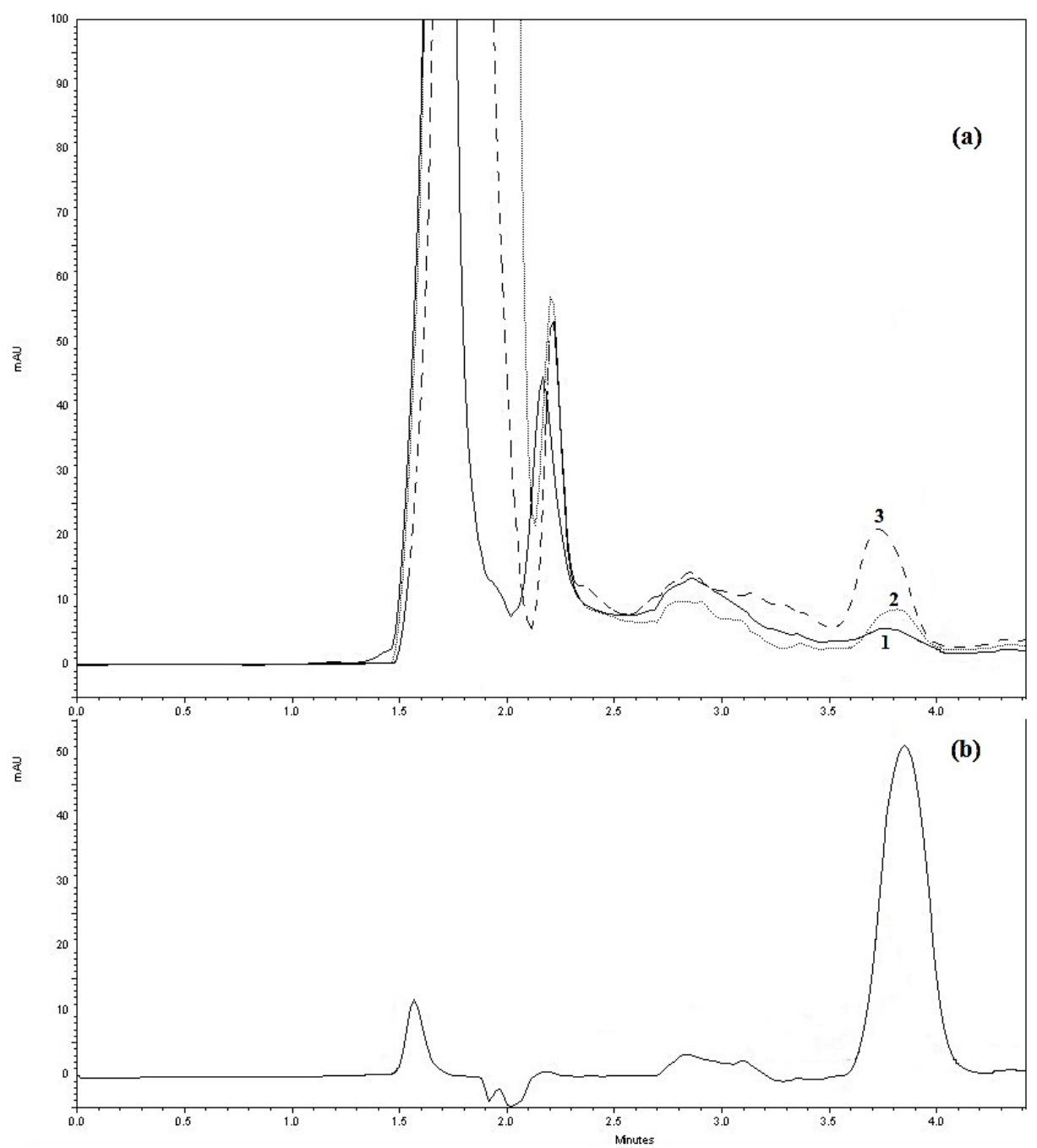

Figure 5. The chromatograms of, a) the landfill leachate sample from Babolsar, Iran (ten times diluted), (1) unspiked sample, (2) and (3) the sample spiked with 50 and $100 \mu \mathrm{g} \mathrm{L}^{-1}$ of BPA, respectively and (b) BPA standard $\left(10 \mathrm{mg} \mathrm{L}^{-1}\right)$. Extraction and separation conditions are the same as described in the experimental section. Retention time of BPA: $3.75 \mathrm{~min}$, Detector monitoring wavelength: $215 \mathrm{~nm}$.

Bull. Chem. Soc. Ethiop. 2014, 28(3) 
The results and RSDs of the analyses of BPA in landfill leachate samples are summarized in Table 3. Also, the recoveries of the method for BPA, expressed as the ratios of the concentration of the analyte found (the measured values minus blank values) to the concentration of the analyte spiked, were obtained by spiking the landfill leachate samples with 50 and $100 \mu \mathrm{g} \mathrm{L}^{-1}$ of BPA, followed by the determination of its concentration in the spiked samples with the current method. As displayed in Table 3, the recoveries of this method ranged from $98 \%$ to $109 \%$ and the RSDs ranged from $1 \%$ to $5 \%$. These results demonstrate the efficiency and the applicability of the present method for BPA evaluation in landfill leachate samples. Typical chromatograms of unspiked and spiked samples are shown in Figure 5.

Table 3. Determination of BPA in landfill leachate samples.

\begin{tabular}{|l|c|c|c|c|}
\hline \multirow{2}{*}{ Sample } & \multicolumn{2}{|c|}{ BPA amount $\left(\mu \mathrm{g} \mathrm{L}^{-1}\right)$} & RSD & \multicolumn{2}{c|}{$\begin{array}{c}\text { Recovery } \\
(\%)\end{array}$} \\
\cline { 2 - 4 } & Added & Found & $(\%)$ & - \\
\hline Babolsar landfill leachate $^{\mathrm{a}}$ & 0.0 & 101.1 & 5.0 & 108.1 \\
\cline { 2 - 5 } & 50.0 & 163.4 & 2.4 & 109.3 \\
\cline { 2 - 5 } & 100.0 & 219.9 & 3.5 & - \\
\hline Noor landfill leachate & 0.0 & 125.8 & 3.0 & 98.0 \\
\cline { 2 - 5 } & 50.0 & 172.3 & 1.0 & 102.0 \\
\cline { 2 - 5 } & 100.0 & 230.4 & 1.0 & \\
\hline
\end{tabular}

${ }^{\mathrm{a}}$ Ten times diluted

\section{CONCLUSIONS}

In this study, the applicability of DLLME as an efficient preconcentration technique was successfully extended to the complex matrices of landfill leachate samples. DLLME has been proposed as an alternative to the most frequent BPA extraction methods, based on SPE and CPE. DLLME has the advantages of ease of operation, rapidity, reproducibility, low cost, use of fewer amounts of organic solvents (green approach) and high enrichment factors. Despite the complexity of the matrices studied, good recoveries, high reproducibility and interference-free chromatograms were achieved. It provided satisfactory results in terms of accuracy, and as a result, has proved its suitability for the analysis of BPA in landfill leachate samples.

\section{ACKNOWLEDGMENT}

The author thanks the research council at the Payame Noor University for financial support.

\section{REFERENCES}

1. Schug, T.T.; Janesick, A.; Blumberg, B.; Heindel, J.J. J. Steroid. Biochem. Mol. Biol. 2011, 127, 204.

2. Casajuana, N.; Lacorte, S. J. Agr. Food. Chem. 2004, 52, 3702.

3. Ballesteros-Gómez, A.; Rubio, S.; Pérez-Bendito, D. J. Chromatogr. A 2009, 1216, 449.

4. Burridge, E. Eur. Chem. News 2003, 17, 14.

5. Ahn, Y.G.; Shin, J.H.; Kim, H.Y.; Khim, J.; Lee, M.K.; Hong, J. Anal. Chim. Acta 2007, 603, 67.

6. Lang, I.A.; Galloway, T.S.; Scarlett, A.; Henley, W.E.; Depledge, M.; Wallace, R.B.; Melzer, D. J. Am. Med. Assoc. 2008, 300, 1303.

7. European Food Safety Authority, EFSA J. 2006, 428, 1. 
8. Integrated Risk Information System (IRIS), Bisphenol A (CASRN 80-05-7), U.S. Environmental Protection Agency, Washington, DC: 1988. Available at: http://www.epa.gov/iris/subst/0356.htm.

9. EEC, Commission Directive 2004/19/EC Off. J. Eur. Communities 2004, L71, 8.

10. Sajiki, J.; Takahashi, K.; Yonekubo, J. J. Chromatogr. B 1999, 736, 255.

11. Sambe, H.; Hoshina, K.; Hosoya, K.; Haginaka, J. Analyst 2005, 130, 38.

12. Zhang, J.; Cooke, G.M.; Curran, I.H.A.; Goodyer, C.G.; Cao, X.L. J. Chromatogr. B 2011, 879, 209.

13. Ouchi, K.; Watanabe, S. J. Chromatogr. B 2002, 780, 365.

14. Zhao, M.P.; Li, Y.Z.; Guo, Z.Q.; Zhang, X.X.; Chang, W.B. Talanta 2002, 57, 1205.

15. Yin, H.; Cui, L.; Ai, S.; Fan, H.; Zhu, L. Electrochim. Acta 2010, 55, 603.

16. Zhou, J.K.; Zhang, Q.L.; Han, K.; Zhang, L.; Zhao, F.B. Sci. Technol. Food Ind. 2007, 28(2), 233.

17. Cao, X.L.; Corriveau, J.; Popovic, S.; Clement, G.; Beraldin, F.; Dufresne, G. Agric. Food Chem. 2009, 57(12), 5345.

18. Zhong, S.; Tan, S.N.; Ge, L.; Wang, W.; Chen, J. Talanta 2011, 85, 488.

19. Kim, D.; Han, J.; Choi, Y. Anal. Bioanal. Chem. 2013, 405, 377.

20. Kawaguchi, M.; Ito, R.; Endo, N.; Okanouchi, N.; Sakui, N.; Saito, K.; Nakazawa, H. J. Chromatogr. A 2006, 1110(1-2), 1.

21. Rezaee, M.; Assadi, Y.; Milani, M.R.; Aghaee, E.; Ahmadi, F.; Berijani, S. J. Chromatogr. A, 2006, 1116,1 .

22. Rahnama Kozani, R.; Assadi, Y.; Shemirani, F.; Milani Hosseini, M.R.; Jamali, M.R. Chromatographia 2007, 66, 81.

23. Jamali, M.R.; Assadi, Y.; Rahnama Kozani, R. J. Chem. 2013, in press.

24. Mashkouri Najafi, N.; Tavakoli, H.; Alizadeh, R.; Seidi, Sh. Anal. Chim. Acta 2010, 670, 18.

25. Zhou, Q.; Zhao, N.; Xie, G. J. Hazard. Mater. 2011, 189, 48.

26. Zhang, Y.; Duan, J.; He, M.; Chen, B.; Hu, B. Talanta 2013, 115, 730.

27. Xiangli, L.; Li, L.; Shichun, Z.; Chongyu, L.; Tiangang, L. Chin. J. Anal. Chem. 2006, 34, 325.

28. Li, N.; Lee, H.K. Anal. Chem. 1997, 69, 5193.

29. Sambe, H.; Hoshina, K.; Hosoya, K.; Haginaka, J. J. Chromatogr. A 2006, 1134, 16.

30. Akita, S.; Takeuchi, H. Sep. Sci. Technol. 1995, 30, 833.

31. Zhoua, Q.; Gao, Y.; Xie, G. Talanta 2011, 85, 1598.

32. Rezaee, M.; Yamini, Y.; Shariati, S.; Esrafili, A.; Shamsipur, M. J. Chromatogr. A 2009, 1216, 1511.

33. Naseri, M.T.; Hemmatkhah, P.; Milani Hosseini, M.R.; Assadi, Y. Anal. Chim. Acta 2008, $610,135$.

34. Mei, S.; Wu, D.; Jiang, M.; Lu, B.; Lim, J.M.; Zhou, Y.K.; Lee, Y.I. Microchem. J. 2011, 98,150

35. Geng, Y.; Ding, M.; Chen, H.; Li, H.F.; Lin, J.M. Talanta 2012, 89, 189.

36. Tan, F.; Zhao, H.; Li, X.; Quan, X.; Chen, J.; Xiang, X.; Zhang, X. J. Chromatogr. A 2009, 1216, 5647.

37. Fan, Y.; Feng, Y.Q.; Shi, Z.G.; Wang, J.B. Anal. Chim. Acta 2005, 543, 1.

38. Basheer, Ch.; Lee, H.K. J. Chromatogr. A 2004, 1057, 163.

39. Kawaguchi, M.; Ito, R.; Okanouchi, N.; Saito, K.; Nakazawa, H. J. Chromatogr. B 2008, $870,98$.

40. Chen, M.; Tao, L.; Collins, E. M.; Austin, Ch.; Lu, Ch. J. Chromatogr. B 2012, 904, 73.

41. APHA, Standard Method for Examination of Water and Wastewater, American Public Health Association: Washington, D.C.; 1998. 